\title{
APROPRIAÇÃO DE UMA VARIANTE ESTILÍSTICA COMO PROCESSO IDENTITÁRIO EM PÁGINA DO FACEBOOK
}

\author{
APPROPRIATION OF A STYLISTIC VARIANT AS IDENTARY PROCESS ON FACEBOOK PAGE
}

\author{
Oscar Felipe Rodrigues Ribeiro \\ Universidade Estadual de Maringá, Maringá, PR, Brasil. E-mail: oscarfelipe45@gmail.com
}

DOI: https://doi.org/10.46550/amormundi.v2i2.68

Recebido em: 03.02.2021

Aceito em: 29.02.2021

\begin{abstract}
Resumo: Seja para se sentir pertencente ou para se adaptar as regras do grupo social, o falante é capaz de modificar sua fala, ou seja, fazer uso de diferentes estruturas linguísticas. Desse modo, busca-se investigar, dentro de um contexto específico, como os usuários modificam sua fala de acordo com a situação na qual se encontram. O objeto foi gerado nas postagens da rede social Facebook em um grupo intitulado "Grupo onde fingimos ser idosos confusos com a tecnologia". Apresenta-se, também, o enquadramento metodológico, já que é necessário em pesquisas que levam em consideração o trabalho com variações linguísticas, além de levantar alguns questionamentos sobre os tipos de variação, formação de identidade e como tais processos são observados no objeto de estudo. Os dados mostram diferenças significativas entre as postagens dos usuários no grupo e suas páginas pessoais na rede social supracitada.
\end{abstract}

Palavras-chave: Variante estilística; Facebook; Formação de Identidade; Monitoramento Linguístico.

\begin{abstract}
Whether to feel belonging or to adapt the rules of the social group, the speaker is able to modify his speech, that is, make use of different linguistic structures. Thus, we seek to investigate, within a specific context, how users modify their speech according to the situation in which they find themselves. The object was generated in the posts of the social network Facebook in a group entitled "Group where we pretend to be elderly confused by technology". The methodological framework is also presented, as it is necessary in research that takes into account work with linguistic variations, in addition to raising some questions about the types of variation, identity formation and how these processes are observed in the object of study. . The data shows significant differences between users' posts in the group and their personal pages on the aforementioned social network.
\end{abstract}

Keywords: Stylistic variant; Facebook; Identity Formation; Linguistic Monitoring.

\section{Introdução} trabalho do professor é guiar o aluno para os mais diversos saberes científicos.
Em se tratando de professor de linguagens, uma das funçóes é ensinar o aluno os mais diversos gêneros presentes na sociedade. $O$ trabalho com gênero pode seguir várias vias metodológicas, cabe o professor conhecer sua turma para que assim aplique um ensino adequado e eficaz.

Uma das possibilidades de trabalho com os gêneros é para a aquisição ortográfica nas 
séries iniciais. Porém, Matos e Silva (2003) ressaltam que esse processo pode ser influenciado pelo contexto social e o processo escolar. Portanto, os autores defendem que cabe ao professor, dentro do seu processo de formação, tornarem os alunos conscientes dasmúltiplas formas de comunicação nos mais diferentes contextos. Mas como ensinar o alunoa moldar sua identidade nas mais diversas circunstâncias de vidas e, assim, adequar sua linguagem? Os alunos, ou pessoas no geral, são capazes de fazerem uso de variaçôes linguísticas dependendo das relaçôes que estabelecem umas com as outras?

A fim de contribuir com tais questionamentos, o presente artigo visa analisar como o contexto pode influenciar na utilização de diferentes variaçôes linguísticas. Seja para se sentir pertencente ou para se adaptar as regras do grupo social, o falante é capaz de modificar sua fala, ou seja, fazer uso de estruturas linguísticas diferentes? Para isso,buscar-se-á investigar dentro de um contexto específico (páginas do Facebook) e observar se os usuários modificam sua fala de acordo com a situação no qual se encontram.

Para o estudo, a divisão deste artigo se dá em um primeiro momento na fundamentação teórica, em que se resgatam algumas definiçôes sobre a rede social analisada (Facebook). Apresenta-se, também, o enquadramento metodológico, já que é necessário em pesquisas que levam em consideração o trabalho com variaçóes linguísticas, além de levantar alguns questionamentos sobre os tipos de variação, formação de identidade e como esses processos são observados no objeto de estudo. Na parte da análise, busca-se levantar diferenças e semelhanças entre os 5 usuários da página do Facebook explorada, como esses se comportam em pronunciar enunciados dentro de suas páginas pessoais e no grupo de análise. Já as consideraçôes finais, essa é designada para algumas reflexóes sobre as múltiplas identidades dos usuários de língua portuguesa brasileira.

\section{Aporte teórico}

Antes de adentrarmos na análise proposta pelo presente artigo, faz-se necessário retomarmos alguns conceitos. Primeiramente, o corpus utilizado foi extraído de uma página do Facebook intitulada "Grupo onde fingimos ser idosos confusos com a tecnologia”. A empresa Facebook, criada em fevereiro de 2004, se auto denomina como uma ferramenta cuja intenção é

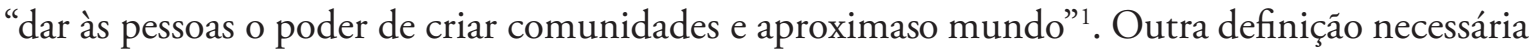
é acerca dos grupos disponíveis na página em questáo. O Facebook os definem como:

Os grupos fornecem um espaço para as pessoas conversarem sobre interesses em comum. É possível criar grupos para qualquer coisa, como reunióes de família, equipe esportiva com os colegas de trabalho, clube delivros, e personalizar as configuraçóes de privacidade do grupo de acordo com quem você deseja que participe e veja o grupo. Se você for um administrador do grupo, este será o local onde poderá encontrar recursos úteis do Facebook para aumentar e se envolver com suas comunidades ${ }^{2}$.

Com o intuito de conectar as pessoas, os grupos possuem diversos objetivos. Como a própria definição diz, cria-se grupos para qualquer coisa. As regras de interação são definidas

1 Informação extraída da página oficial do Facebook. Disponível em: https://www.facebook.com/pg/FacebookBrasil/ about/?ref=page_internal. Acesso em 12/08/2019

2 Informação extraída da página oficial do Facebook. Disponível em: https://www.facebook.com/ help/1629740080681586/?helpref=hc_fnav. Acesso em 12/08/2019. 
por seus administradores/criadores. Com mais de 400 mil membros, o grupo analisado tem a intenção de divertir, para isso, a proposta é de criar uma personagem fictícia que utiliza uma variante da língua para a interação via redes sociais. Além disso,ele possui quatro regras: a) não é um grupo de analfabetos; b) não faça posts repetidos; c) denuncie comentários e postagens fora do contexto e d) utilize parênteses para sair da personagem.

Os usuários selecionados têm entre 20 a 26 anos de idade, por isso cabe salientar as diferenças linguísticas entre falantes de idades diferentes. Sobre isso, Labov (2008), ao estudar o contexto de Martha’s Vineyard, constatou que falantes mais idosos preservavam traços fonológicos diferentes dos mais jovens. Para dar fundamento na sua tese, o autor cita alguns trabalhos como os de Bloomfield (1933) que afirmava não ser possível constatartais mudanças em sua época por falta de tecnologia. Gauchat (1905) e Hermann (1929) que estudaram o mesmo contexto, observaram mudanças fonéticas entre geraçóes. Cabe aqui estudos que tratem com mais clareza mudanças linguísticas entre falantes de geraçóes diferentes, porém, as constataçôes acima, sugerem que há uma diferença na fala entre falantes mais jovem se comparada a fala de falantes mais idosos. Essa constatação é observada no grupo de análise do presente artigo, afinal os usuários creem que a variante estilística utilizada por eles é do público que a comunidade se referencia.

Sobre o uso das variaçóes linguísticas, Bortoni-Ricardo (2005) as concebe sobre dois aspectos: a) ampliar a eficácia na comunicação e b) marcar a identidade social. Comoa intenção do grupo de análise é interagir-se por meio de uma personagem, os membros fazem uso de uma variação cujo objetivo recai mais sobre o aspecto (b) proposto pela autora. Afinal, os usuários apresentam muitas similaridades em uso de recursos linguísticosem suas postagens. Mais adianta, na parte de análise, estas semelhanças serãoexemplificadas.

Outro conceito que cabe mencionar determinante da linguagem utilizada pelosfalantes no grupo do Facebook é o de Comunidade de Prática. Definido por Eckert (2000, apud SEVERO, 2007, p.35), ele é entendido como pessoas que se juntam para um determinado empreendimento. Por apresentarem este objetivo em comum, os membros fazem uso de uma forma de agir e de falar. No objeto de estudo, por estarem conectadospor meio de uma página na internet, os falantes fazem uso da variante linguística que eles acreditam atender os objetivos da comunidade no qual se inseriram. Em outras palavras, enquadram-se no que é proposto pelo autor, utilizam-se de uma forma de agir e falar condizente com a comunidade que estáo inseridos.

A autora expóe também que a comunidade de prática se caracteriza por três vertentes: 1) engajamento mútuo - ou seja, os membros do grupo mostram-se interessados em se entreter; 2) negociação de interesses e propósitos - não há uma obrigação em sefazer parte da comunidade, só está nela quem tem interesse e, por isso, podemos supor umanegociaçáo implícita em que o falante, ao adentrar no grupo, é puramente volitivo; 3) troca de repertório - como constataremos na análise, vê-se muitas semelhanças entre o uso de certos elementos linguísticos que os falantes creem ser uma variante da língua pertencente do público que a comunidade se refere, ou seja, dos idosos. Wenger (1998) também define o conceito de comunidades de prática como engajamento que nós, humanos, temos em buscar empreendimentos que garantam os mais diversos objetivos (sobrevivência, prazer individual, etc.). E, a partir de definirmos nossos interesses, há interação com os outros indivíduos e com o mundo, culminando assim emum aprendizado coletivo. 
O aprendizado resulta em práticas que, por sua vez, estabelecem um tipo de comunidade que busca, continuamente, um objetivo compartilhado. Assim, o autor chama essas comunidades de comunidade de prática.

As relações estabelecidas por Wenger (1998) também são constatadas no objeto de análise do presente artigo. O empreendimento estabelecido pelo grupo tem o intuito de divertir/ interagir. As interaçóes se dão via comentários que geram um aprendizado coletivo. Afinal, ao comentar e/ou se deparar com uma postagem, o falante se apropria da variante utilizada e a utiliza para interagir uns com os outros criando uma rede e ampliandoa linguagem. O aprendizado gera novas postagens e, assim, estabelece uma comunidade com as práticas compartilhadas.

Além disso, Wenger (1998) relaciona a comunidade de prática com a formação de identidade. $\mathrm{O}$ autor mostra que o sujeito para fazer parte de uma dada comunidade, precisa ser reconhecido como participante. Para isso, há uma negociação (silenciosa ou aberta) da maneira de ser no contexto. Ou seja, o membro tem a sua identidade formada ao se adaptar às características da comunidade. Wenger (1998) traz ainda alguns tipos de formaçáo de identidade, como pode ser observado no quadro a seguir.

Quadro 1 - Tipos de identidade e suas formaçôes

\begin{tabular}{|l|l|}
\hline IDENTIDADE & FORMAÇÃO \\
\hline Identidade como experiência negociada & $\begin{array}{l}\text { Definida por meio de participação social e pela } \\
\text { forma no qual os outros nos reificam. }\end{array}$ \\
\hline Identidade como membro da comunidade & Definida pelo contexto familiar e não familiar. \\
\hline Identidade como trajetória de aprendizagem & $\begin{array}{l}\text { Definida pelos caminhos nos quais o sujeito } \\
\text { foi e pretende ir. }\end{array}$ \\
\hline $\begin{array}{l}\text { Identidade como nexo de multimídia } \\
\begin{array}{l}\text { Identidade como uma relação entre o local e o } \\
\text { global }\end{array}\end{array}$ & $\begin{array}{l}\text { Definida pela capacidade do indivíduo } \\
\text { conciliar várias formas de associação em umaúnica } \\
\text { identidade. }\end{array}$ \\
\hline $\begin{array}{l}\text { locais, manifestadas em estilos e } \\
\text { discursos amplos. }\end{array}$ \\
\hline
\end{tabular}

Fonte: Wenger, 1998. (Elaboração própria)

No grupo, de acordo com o quadro 1, as identidades são formadas perpassando os conceitos sugeridos pelo autor. Afinal, caracterizam-se por uma participaçáo social em queoutros sujeitos interagem (reificando o usuário). Além disso, trata-se de um contexto não- familiar (internet) e o falante é quem escolhe traçar esse percurso. Por fim, vê-se um caráter multiforme nas identidades e, por precisarem criar um personagem fictício da terceira idade, muito usuários acabam se espelhando em alguma figura familiar (avó/avô) para executarem tal papel fazendo uso dos recursos linguísticos estabelecidos na comunidade de prática.

Le Page (1980, apud BORTONI-RICARDO, 2005, p.96) trata o ato de fala como um ato de identidade. Afinal, o falante circunda sua fala mobilizando estruturas linguísticasque se assemelham ao grupo de referência, formando assim sua identidade. Ao modificar sua fala, o 
usuário, segundo o autor, recai sobre quarto condições restritivas: a) capacidade de identificação com o grupo; b) o acesso e a capacidade de reproduzir as regras do grupo;

c) a presença de variáveis e motivaçôes conflitantes e; d) capacidade de modificar seu próprio comportamento linguístico.

Por fim, convém citar o conceito de monitoração linguística proposto por BortoniRicardo (2005). Tal expressão, por mais que tenha o objetivo que analisar as variaçóes estilísticas na fala, é válida para o presente artigo, principalmente se levarmos em consideração os fatores nos quais a autora enfatiza. O primeiro deles é a acomodação do falante ao seu interlocutor, no grupo, por se tratar de uma rede social, as postagensapresentam o intuito de interação com outros membros, ou seja, pensa-se no interlocutor para que o mesmo se manifeste (seja via curtida, comentários). O segundo fator é o apoio contextual na produção de enunciados, em outras palavras, o responsável pela postagem adota a linguagem proposta pelo grupo, adequa-se ao contexto. Outro fator que a autora expóe é a complexidade cognitiva envolvida na produção estilística, neste elemento há um certo distanciamento do corpus analisado, salvo pelo fato de que o falante faz uso de uma variante diferente do seu habitual, logo há uma elaboração no enunciado que o torna, de certa forma, mais complexo. Por último, a familiaridade do falante com a tarefa comunicativa, que é de o falante estar inserido no contexto.

\section{Análise}

As postagens foram coletadas no grupo do Facebook intitulado "Grupo onde fingimos ser idosos confusos com a tecnologia". As publicaçóes selecionadas foram feitas por pessoas que cursam ou já terminaram o ensino superior e que possuem idade entre $20 \mathrm{a} 26$ anos, portanto sáo jovens. Com intuito de comparação, além das postagens no grupo, selecionou-se publicaçôes nas páginas pessoas de cada indivíduo. Cabe salientar que os nomes citados a seguir são fictícios, para preservar a identidade de cada um.

Vejamos as postagens do primeiro indivíduo, o João.

Quadro 2 - Postagens do João no grupo e em sua página pessoal

\begin{tabular}{|l|l|}
\hline No grupo & "faço.calendario.com.sua.foto.pra.vende..encomende.o.seu!!!..." \\
\hline $\begin{array}{l}\text { Na pági- } \\
\text { napessoal }\end{array}$ & $\begin{array}{l}\text { "Arma: segurança pra família de bem liberdade coisa linda temos direito vivaas arma } \\
\text { compra arma } \\
\text { Videogame: absurdo violento demais VIDEOGAME MATA proíbe osvideogame } \\
\text { onde já se viu } \\
\text { (que desespero esse país, como elegemos esses caras?!?!?)” }\end{array}$ \\
\hline
\end{tabular}

No quadro 2, tem-se que o João fez uso de uma variante diferente se comprarmos os recursos linguísticos empregados no grupo com os de sua página pessoal. No grupo, observa-se a substituição de espaço (space) por um ponto final, além disso há alguns usos que se destoam de uma variável culta, como por exemplo o não uso do acento tônico em "calendario", verbo "vende" que deveria estar no infinitivo e as exclamaçôes seguidas de três pontos. Já em sua página pessoal, João, ironicamente, incorpora fala de outros sujeitos em sua postagem que também apresentam desvios de uma variante culta, porém há a presença do space entre as palavras, os 
acentos estáo presentes e o texto tem coesão.

Quadro 3 - Postagens do Marcelo no grupo e em sua página pessoal

\begin{tabular}{|l|l|}
\hline No grupo & $\begin{array}{l}\text { "deus ten qui.vouta logo pra.por as coisa em ordem.tem. } \\
\text { piedadi sem or" }\end{array}$ \\
\hline $\begin{array}{l}\text { Na página } \\
\text { pessoal }\end{array}$ & $\begin{array}{l}\text { "gente, desculpa, mas não existe coincidência numa decisão tomada porhéteros e bran- } \\
\text { cos quando a outra parte é preta e gay." }\end{array}$ \\
\hline
\end{tabular}

No quadro 3, acerca das postagens de Marcelo, ele apresenta algumas semelhanças com o analisado anteriormente. Primeiramente, observa-se novamente o uso de ponto final no lugar de space como em "pra.por" e "tem.piedadi". Além disso, o sujeito faz uso deuma variante que também apresenta desvios se comparada a norma culta da língua portuguesa: falta de concordância, como em "as coisa"; erros na escrita, como em "vouta, piedadi, sem or". Porém, na postagem de Marcelo em sua página pessoal, há um nível de monitoramento maior, pois ele atenta-se aos acentos e a escrita correta das palavras, faz o uso de vírgulas para separar os termos nas oraçôes e finaliza a postagem com ponto final.

Quadro 4 - Postagens do Augusto no grupo e em sua página pessoal

\begin{tabular}{|l|l|}
\hline No grupo & "Meu presidento com.o.sem.pre ocupado com a florest.amazonica . Amem .Bjs" \\
\hline $\begin{array}{l}\text { Na napessoal } \\
\text { pági- }\end{array}$ & $\begin{array}{l}\text { "Antes de iniciar essa leitura, me deparei que estou com 70\% do meu curso. O tempo é } \\
\text { um paradoxo: quanto mais se perde, mais se deseja ter. Sinto que a UFMT me deixará } \\
\text { marcas, algumas boas e outras nem tantas, entretanto, elas serão uma prova cabal que algo } \\
\text { maior existiu." }\end{array}$ \\
\hline
\end{tabular}

No quadro 4, Augusto também fez uso de uma variante diferente entre as postagens. $\mathrm{Na}$ publicação do grupo, ele usa alguns recursos que se assemelham aos anteriores, como por exemplo, falta de acento nas palavras (amazonica e amem), mas o ponto final tem duas utilizaçóes, a primeira é igual ao de Marcelo e João, que seria substituir o space, já a outra é de cortar palavras o este recurso linguístico, como em:com.o e sem.pre. Enquanto que em sua página pessoal, a variante estilística utilizada por Augusto é mais monitorada. Ele faz uso de pontuação para separar os elementos das oraçóes, os acentos estão presentes, o texto é coeso e finalizado com ponto final.

Quadro 5 - Postagens do José no grupo e em sua página pessoal

\begin{tabular}{|l|l|}
\hline No grupo & "Meu.netinho Enzo lindinho cheio.de sarna" \\
\hline Na página pessoal & $\begin{array}{l}\text { "Gente, eu vou desmaiar! } \\
\text { Essa mulher é o amor da minha vida" }\end{array}$ \\
\hline
\end{tabular}

No quadro 5, as publicaçóes de José apresentam o mesmo campo semântico, ou seja, falam de assuntos similares - a admiração por alguém. Porém, o tratamento 
linguístico apresenta variação. No grupo, ele apresenta a variante que substitui o space por ponto, como em "Meu.netinho" e, pela publicação, observa-se a troca da palavra sarda por sarna. Já no post feito em sua página pessoal, José monitora sua escrita para ter uma variante próxima a culta. Ele separa o vocativo e não comete nenhum equívoco na escrita.

Quadro 6 - Postagens do Aparecida no grupo e em sua página pessoal

\begin{tabular}{|l|l|}
\hline No grupo & $\begin{array}{l}\text { "AMO,, Q FASO...; MICRO PEGMENTACAO CAPELAR,,! VALOR EMBO- } \\
\text { XES," }\end{array}$ \\
\hline Na página pessoal & $\begin{array}{l}\text { "Na última sexta-feira completei } 26 \text { anos. Sou grata à Deus por tudo que me proporcio- } \\
\text { na, mas principalmente pelos amigos e família maravilhosa que Ele me deu." }\end{array}$ \\
\hline
\end{tabular}

As publicaçóes de Aparecida, expressas no quadro 6, estão em consonância, em termos de variaçóes distintas, com as analisadas até aqui. No grupo, ela emprega osmesmos recursos já mencionados: desvios na escrita padrão, uso excessivo e inadequado (segundo a variante padrão) de pontuação. Por outro lado, a publicação retirada de sua página pessoal, Aparecida apresenta alguns desvios da norma-padrão, porém percebe-se um grau de monitoramento linguístico bem mais elevado.

Quadro 7 - Postagens do Maria no grupo e em sua página pessoal

\begin{tabular}{|l|l|}
\hline No grupo & $\begin{array}{l}\text { "ACHEI.,ENDERESSO MERCADO LIVRE...,,FICA DO LADO } \\
\text { DAVENDA DO OLAVO FIO DO ZE” }\end{array}$ \\
\hline Na página pessoal & $\begin{array}{l}\text { "Além do preço justo e serviços de qualidade, ao contratar uma EJ você ajudana for- } \\
\text { maçáo de líderes do futuro. Precisa de mais motivos? Contrate uma EJ!” }\end{array}$ \\
\hline
\end{tabular}

Como observado anteriormente, o quadro 7 também apresenta variação linguística entre a postagem feita por Maria no grupo e a feita em sua página pessoal. Na publicação do grupo, Maria fez uso da variante diferente culta, e seus recursos linguísticos sãosimilares já observados até aqui.

\section{Consideraçóes finais}

As discussóes abordadas no presente artigo, nos faz refletir sobre alguns pontos significativos. Primeiramente, o uso das redes sociais proporciona aos usuários um contato com diferentes comunidades de prática e, com isso, acarretando em mudanças linguísticas, tanto na fala quando na escrita. Afinal, para fazer parte de dada comunidade, o falante precisa adaptar sua linguagem a fim de se fazer notar/aceito.

Outro fato importante que se pode observar é o uso de variantes da língua portuguesa. Com isso, constata-se que o falante é capaz de perpassar entre diferentes variaçóes da língua, ou seja, para se adequar a uma comunidade, o usuário da língua acaba aprendendo como esta comunidade se comporta (comportamentos, crenças, valores, língua e etc.) para poder se igualar e, assim, pertencer ao grupo.

Se formos transpassar tais constataçóes para o ensino, há de se crer que nem sempreo 
aluno faz uso da variante escolar, seja por não se sentir pertencente a ela ou por não conseguir adquiri-la. O papel do professor entáo, é fazer com que com possíveis distâncias entre a variaçáo da língua que o aluno possui e a que é exigida na escola sejam aproximadas. Isso pode ser por meio de metodologias que abarquem os conhecimentos queos alunos já possuem com os saberes que serão ensinados na escola. Afinal, Barbosa (2014), constata que o ambiente escolar é formado por saberes (vernacular, descritivo e científico) e cabe o professor conciliá-los para proporcionar um ensino dinâmico e abrangente. Porém, essas são discussóes/sugestôes para próximas pesquisas.

\section{Referências}

BARBOSA, A. G. Saberes Gramaticais na escola. In: VIEIRA, S. R.; BRANDÃO, S. F. Ensino de gramática: descriçáo e uso. 2. ed. São Paulo: Contexto, 2014, p. 31-54.

BORTONI-RICARDO, Stella Maris. Nós cheguemu na escola, e agora? São Paulo: Parábola Editorial, 2005.

LABOV, W. Padróes Sociolingüisticos. Traduçao Marcos Bagno; Maria Marta Pereira Scherre; Caroline Rodrigues Carboso. São Paulo. Parábola Editorial. 2008.

MATOS e SILVA, R. V. Alguns aspectos da heterogeneidade dialetal brasileira e sua relação com o ensino de português. In: MATOS e SILVA, R. V._Contradiçóes no ensino de português: a língua que se fala X a língua que se ensina. 6. ed. São Paulo: Contexto, 2003, p. $52-77$.

SEVERO, C. G. A questão da identidade e o lócus da variação-mudança linguística em diferentes abordagens sociolinguísticas. In: Letra Magna: Revista Eletrônica de Divulgaçáo Científica em Língua Portuguesa, Lingüística e Literatura - Ano 04 n.07 - 2o Semestre de 2007.

WENGER, E. Intro I: The concept of practice. In: Communities of Practice: Learning, Meaning, and Identity (Learning in Doing: Social, Cognitive and Computational Perspectives. Cambridge: Cambridge University Press. 1998. p. 45-50. 